\title{
Decreasing incidence of burn injury in a rural state
}

\author{
D E Clark, C N Dainiak, S Reeder
}

\begin{abstract}
Objectives-To determine changes in the incidence of burn injury since the regionalization of burn care and intensification of fire prevention initiatives that occurred in Maine during the 1970 s.

Methods-Death certificate data from Maine and the United States for deaths due to fire or burns were obtained for 1960-98. Hospitalization and burn registry data were obtained for Maine from 197398. Frequencies and incidence rates were compared over time and, where possible, between Maine and the United States.

Results-During 1960-79, annual burn mortality in Maine averaged 5.1/100 000, with random variation. After this, the rate declined steadily to an average annual level of 1.4/100 000 during 1993-96. For the entire United States, average annual mortality declined from 4.2/100 000 during 1961-64 to $1.5 / 100000$ during 1993-96. Reduction in mortality has been principally due to prevention of dwelling fires. Hospitalization for burns in Maine was $34.8 / 100000$ during 1973-76 and declined to $10.6 / 100000$ during $1995-98$.

Conclusions-Burn prevention measures have dramatically reduced the incidence of death and hospitalization resulting from burns in Maine.

(Injury Prevention 2000;6:259-262)
\end{abstract}

Keywords: burn; fatality; epidemiology; surveillance

We previously reported a reduction in death and hospitalization rates due to fire and burns in the state of Maine between the 1970s and 1980 s, after the institution of prevention efforts and regionalization of burn treatment. ${ }^{1}$ The present study adds an additional 10 years of data combined from several sources, allowing a more detailed description than would be available from vital statistics alone. The successful reduction in burn incidence we describe may have important implications for other injury control efforts.

\footnotetext{
Department of Surgery, Maine Medical Center, Portland, Maine, USA D E Clark

C N Dainiak

S Reeder

Correspondence to: Dr David E Clark, Department of Surgery, Maine Medical Center, 887 Congress Street, Portland ME 04102, USA

(clarkd@poa.mmc.org)
}

The history of burn prevention and regionalization in Maine during the 1970s is described in an earlier publication. ${ }^{1}$ Maine is heavily forested, has many wood frame houses, and has cold winters. The oil embargos of 1973 and 1978 led to an increase in home heating with wood, which, in turn, led to the institution of new burn prevention programs, especially smoke detectors. At about the same time, burn care resources were reorganized, including creation of a burn unit at the MMC. During the 1980s, burn education in the schools received more attention, and referral of major thermal injuries to centers in Boston became more frequent.

\section{Methods}

As part of our earlier study, discharge abstract data had been received from the Maine Health Care Finance Commission for the years 1973-78 and 1980-88 for all patients with any burn injury diagnosis (International Classification of Diseases, 9th revision (ICD-9), diagnosis codes 941-946 or 948-949). The data include age, date of admission, hospital, length of stay, five diagnosis codes, and outcome. Discharge abstracts are now maintained by the Maine Health Data Organization (MHDO), which was asked to provide similar information as computer files for 1980-98 after approval of a confidentiality agreement. These files were also used to verify the printout data for 198088; where minor discrepancies were found, MHDO data were used for this study.

More detailed information on patients at the MMC was obtained from a burn registry, which had been maintained since 1977 and had been integrated into a trauma registry starting in 1990. Disposition, age, and burn size for patients treated or stabilized at the MMC, including most of those eventually transferred out of state, was available in the MMC registry. Survival data for patients referred from Maine to the Massachusetts General Hospital, Shriners Burns Hospital, or Brigham and Women's Hospital in Boston were also obtained from registries at these institutions.

Death certificate data for 1980-97 for all unintentional cases due to fire or hot substances (International Classification of Diseases, 8th revision (ICD-8), codes E916-E918 until 1978 and ICD-9 codes E890-E899, E924, and E926 after 1979) were obtained from publications of the Maine Office of Data, Research, and Vital Statistics. ${ }^{2}$ Comparable national burn mortality and population data were obtained from Vital Statistics of the United States for years up to 1992, and through the Centers for Disease Control world wide web site for 199396. ${ }^{34}$ 


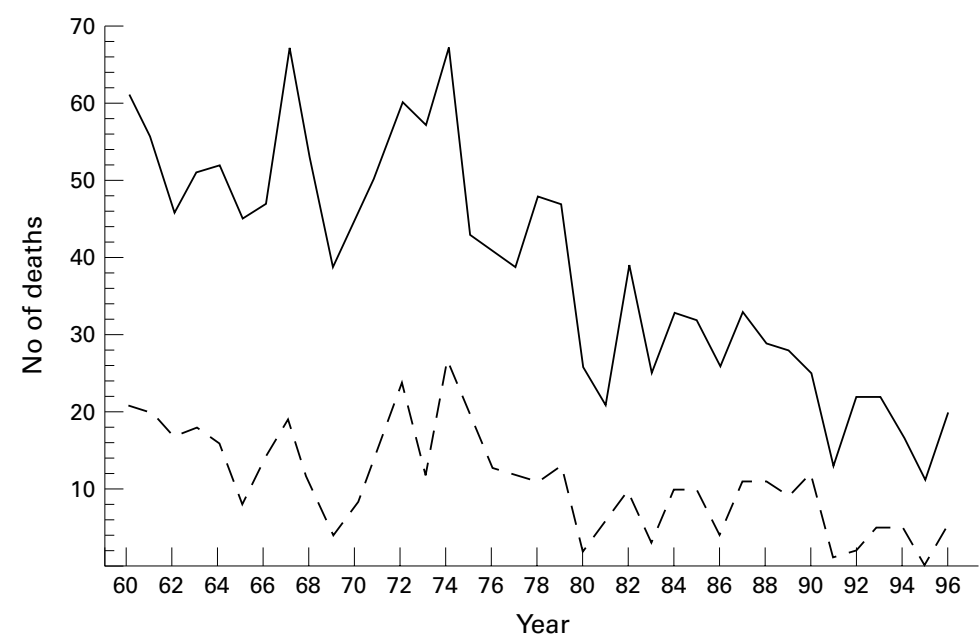

Figure 1 Annual number of deaths from fire or flames (ICD-9 E890-E899) or contact with hot object or fluid (ICD-9 E924) for Maine. Solid line indicates total number and dashed line indicates victims less than 15 years old.

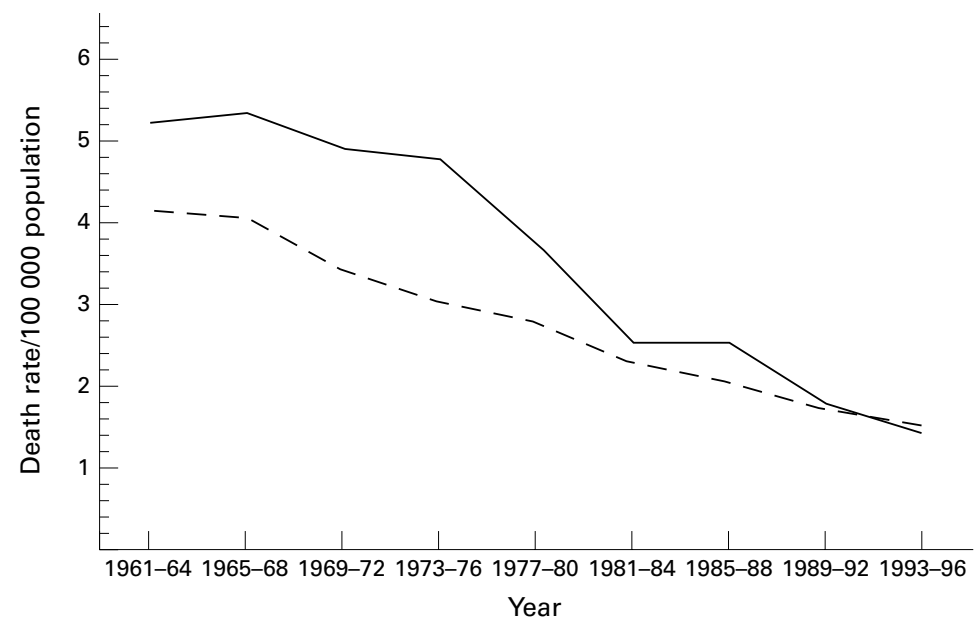

Figure 2 Death rate/100 000 population from fire or flames calculated for Maine (solid line) and for the United States (dashed line), for all ages.

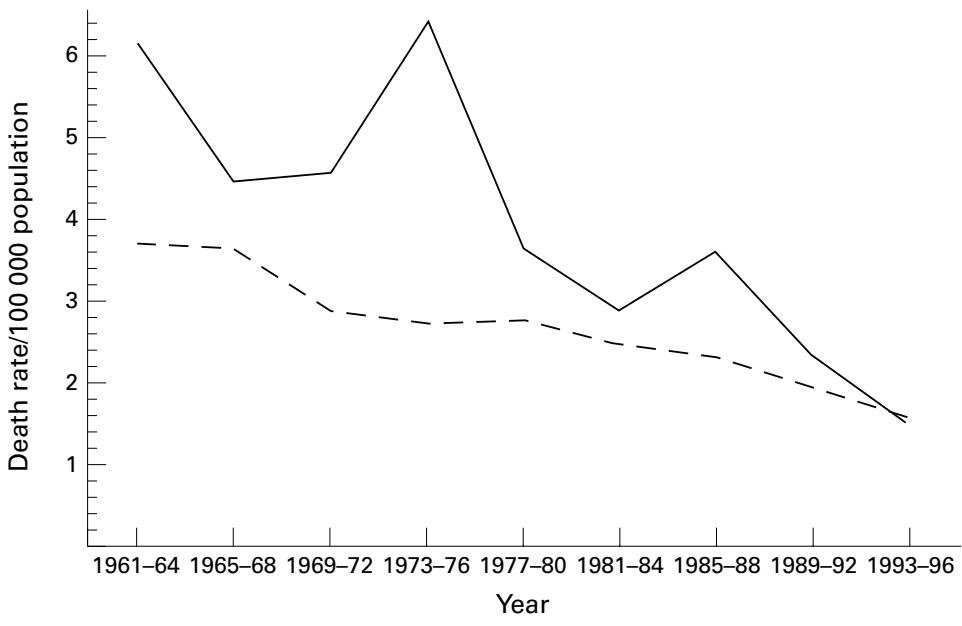

Figure 3 Death rate/100 000 population from fire or flames calculated for Maine (solid line) and for the United States (dashed line), age less than 15.

\section{Results}

The population of Maine has grown from 969000 , with 311000 (32\%) under the age of 15 in the 1960 census, to an estimated 1241000 with 252000 (20\%) under the age of 15 in 1995. In the United States, there were
179.3 million people ( $31 \%$ under the age of 15 ) in the 1960 census, and an estimated 263.4 million people, with $22 \%$ under the age of 15 , in 1995.

The number of deaths per year attributable to burns in Maine ranged between 39 and 67 over the two decades 1960-79, with a frequency distribution consistent with a random binomial process having a mean equal to approximately 51 . Almost all of these deaths were attributed to fire rather than to hot objects or substances. Since 1979, however, the number of deaths has not exceeded 39 and has declined further to an average of 13 annually during 1991-96. Burn deaths in children under the age of 15 years have also declined, from an annual mean of 12 during 1960-79, to an annual mean of three during 1991-96. These changes are depicted in fig 1 .

The rate of death from fire and burns in Maine has also steadily declined since 1979 (fig 2). During 1960-79, the rate was about 5.1 burn deaths/100 000 population. During 1993-96, it was approximately $1.4 / 100000$. By comparison in the United States as a whole, the crude annual mortality rate for fire and burns steadily decreased from 4.2/100 000 during 1961-64 to $1.5 / 100000$ during 1993-96. Similar reductions in mortality have been seen in all age groups, including children (fig 3 ).

The risk ratio comparing the incidence of fatal burns in the Maine population to the incidence in the population of the other United States was 1.26 (95\% confidence interval (CI) 1.09 to 1.44 ) for $1961-64$. It was still 1.57 (95\% CI 1.36 to 1.80 ) for $1973-76$, but then fell to 0.95 ( $95 \%$ CI 0.74 to 1.20 ) by $1993-96$, which is no longer significantly different. The risk ratios for children were similar.

Hospitalization as a result of burn injury also decreased steadily after 1973, with a particularly major change noted in the smaller hospitals. Figure 4, based on discharge abstract data, depicts the total annual numbers of patients admitted with a principal diagnosis of burn injury (ICD-9 diagnosis codes 941-946 or 948-949) and the fraction of these admitted to the MMC. The rate of hospitalization for burns in Maine was 34.8/100 000 during 1973-76 and has declined to $10.6 / 100000$ in 1995-98. Admissions to Boston hospitals obviously do not generate a Maine discharge abstract, but would add less than one case/100 000 per year to these figures.

Although burn admissions to Maine hospitals other than the MMC have decreased, the MMC total remained relatively constant. The median length of stay for patients treated at the MMC (excluding subsequent transfers) decreased from 15 days in 1977-88 to 12 days in 1989-97. Survival and number of patients categorized by age and burn size are depicted in table 1, on the assumption that all patients with greater than $15 \%$ body surface burns were treated at the MMC or in Boston. In none of these cells is the difference in the proportion of patients surviving during 1989-97 significantly different than during 1977-88 (Fisher's exact test, $\mathrm{p}>0.05$ ). 


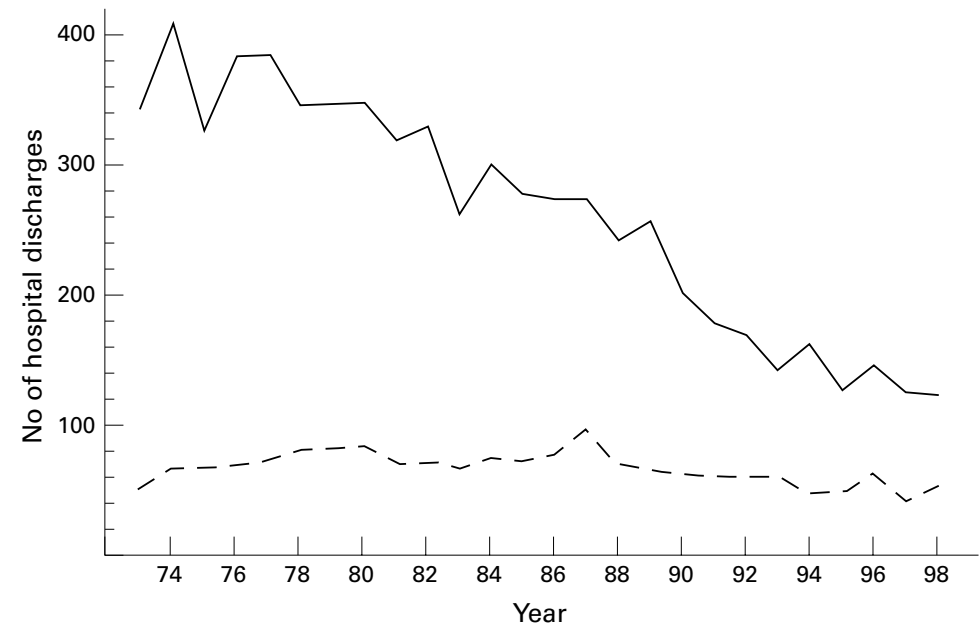

Figure 4 Annual number of hospital discharges for calendar years with principal diagnosis of burn injury (ICD-9 941-946, 948-949), both for the MMC (dashed line) and for all Maine hospitals (solid line) able for many years, morbidity data from hospital registries and administrative abstracts are more recent additions. Potential deficiencies in all these data sources have been previously discussed, ${ }^{16}$ but we found that combining several sources of data helps to mitigate the weaknesses of any individual source. $^{7}$

We noted a decade ago that mortality from burns was decreasing in Maine, and the inclusion of additional years of data supports the impression that prevention efforts, begun in the 1970s, were effective. From 1960-79, the population of Maine grew slowly, while the annual number of burn deaths ranged between 39 and 67 . Thereafter, the population continued to grow slowly, but the number of burn deaths was never again over 39 and continued to decrease, consistent with a significant change in the previously stable process. ${ }^{8}$

Burn mortality for the United States as a whole has also decreased over these years, but Maine has improved from having one of the highest rates of burn mortality to approximately the national average. Because $76 \%$ of the burn deaths in Maine from 1973-80 occurred at structural fires, ${ }^{1}$ we conclude that prevention of these fires and/or escape of potential victims alerted by smoke detectors are the probable causes of the improvement. Surveillance data for fire incidence in Maine have only recently been compiled. ${ }^{9}$ They indicate that most fires still involve single family, wood frame dwellings. Unfortunately, comparative historical data are unavailable. Although smoke detectors were rarely seen in private homes before the 1970s, an estimated $96.4 \%$ of Maine homes had at least one smoke detector in 1995, compared with $94.1 \%$ nationally. ${ }^{10}$ Although data are incomplete, a functional smoke detector was present in only a minority of reported house fires in Maine in 1997-98. ${ }^{9}$

Data from 1985 and 1993 demonstrate that the prevalence of cigarette smoking in Maine has remained constant at $29 \%$, despite a decline in smoking prevalence nationally. ${ }^{11}$ In spite of the fact that fires from smoking materials still remain the leading cause of fire deaths nationally, ${ }^{12}$ the decreasing mortality and morbidity in Maine cannot be attributed to a decrease in cigarette smoking.

Nationally, between 1992 and 1996, fires caused by children playing were the leading cause of burn mortality in those under age $9 .{ }^{12}$ It is interesting to note that the absolute numbers of children have decreased in the past 35 years, as well as the percentage of the population age 15 and under, both in Maine and in the United States as a whole. Although the number and proportion of fire deaths attributable to children have decreased, changes in population distribution cannot account for the more rapid rate of improvement in Maine.

Hospitalization data were used in this study as a surrogate for the incidence of serious nonfatal burn injury. The rate of hospital admission for burns has also shown a decrease in Maine; national data for comparison over this
Epidemiologic study of injuries (including burns) requires the use of many sources of data. ${ }^{6}$ Although mortality data have been avail- 
time period are not available, but would probably show a similar trend. Obviously, it is possible that more minor burn injuries are being treated in an outpatient setting today compared with 25 years ago, but the decrease in every category of age and severity, including those very unlikely to be treated without hospitalization, suggests strongly that there has been a major decrease in morbidity as well as mortality.

Regionalization of burn care has been largely accomplished in New England. Although the number of admissions to specialized hospitals has been fairly constant, the average severity is decreasing. Organized burn care has been previously shown to improve survival, ${ }^{13}{ }^{14}$ but has a minimal population effect compared with prevention. We cannot claim that further improvements in medical care in the past decade have been responsible for the continued improvement in survival, and no evidence for such an effect was found in a recent study from the Massachusetts General Hospital. ${ }^{15} 16$

\section{Implications for prevention}

Overall, it is likely that the decreases in mortality and morbidity from fire and burns in our state and nation are due largely to the increasing use of smoke detectors and improvements in building codes since the 1970s, rather than to any change in clinical management. Due to a lack of historical surveillance data, we are unable to judge the efficacy of other fire education and prevention efforts. Burn treatment centers should expect to see fewer and less severe injuries if these trends occur nationally, and regionalization of care for the complex but decreasingly frequent massive burn injuries is clearly important. The major decreases in mortality and morbidity from fire and burns constitute a significant public health success over the past few decades.

\section{Key points}

- From the mid-1970s to the mid-1990s, annual mortality from fire and burns fell from 5.1 to $1.4 / 100000$.

- From the mid-1970s to the mid-1990s, annual incidence of hospitalization for burns fell from 34.8 to 10.6/100 000 .

- Most burns requiring hospital care are now treated in specialized centers.

1 Clark DE, Katz MS, Campbell SM. Decreasing mortality and morbidity rates after the institution of a statewide burn program. F Burn Care Rehabil 1992;13:261-70.

2 Maine Offices of Health Data and Program Management and Data, Research, and Vital Statistics. Anmual statistical report. Augusta, ME: Maine Department of Human report. Augusta, ME: Maine Department
Services, Bureau of Health, annually 1960-96.

3 US Department of Health and Human Services: National Center for Health Statistics. Vital statistics of the United States. Hyattsville, MD: US Department of Health and Human Services, annually, 1960-92.

4 Centers for Disease Control and Prevention. http:// wonder.cdc.gov.

5 Clark WR, Fromm BS. Burn mortality. Acta Chir Scand 1987;153(suppl 537):1-126.

6 Brigham PA, McLoughlin E. Burn incidence and medical care use in the United States: estimates, trends, and data sources. F Burn Care Rehabil 1996;17:95-107.

7 Clark DE, Hahn DR. Hospital trauma registries linked with population-based data. $\mathcal{F}$ Trauma 1999;47:448-54.

8 Clark DE, Cushing BM, Bredenberg CE. Monitoring hospital trauma mortality using statistical process control methods. $\mathcal{F}$ Am Coll Surg 1998; 186:630-5.

9 Maine Fire Chiefs Association. Maine fire incident reporting system. Augusta, ME: Maine Association of Fire Chiefs and system. Augusta, ME: Maine Association
Sunpro Fire Service Software, 1997-98.

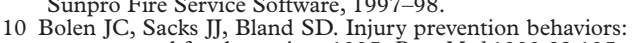
a report card for the nation, 1995. Prev Med 1999;29:195201.

11 Shopland DR, Hartman AM, Gibson JT, et al. Cigarette smoking among US adults by state and region: estimates from the current population survey. I Natl Cancer Inst 1996;88: 1748-58.

12 Hall JR Jr. Patterns of fire casualties in home fires by age and sex, 1992-96. Quincy, MA: National Fire Protection Association, 1999.

13 Demling RH. Burns. N Engl F Med 1985;313:1389-98.

14 Tompkins RG, Schoenfeld DA, Behringer GC, et al. Prompt eschar excision: a treatment system contributing to reduced burn mortality. Ann Surg 1986;204:272-81.

15 Ryan CM, Schoenfeld DA, Thorpe WP, et al. Objective estimates of the probability of death from burn injuries. $N$ Engl mates of the probability
$\mathcal{J}$ Med $1998 ; 338: 362-6$

16 Ryan CM, Schoenfeld DA, Cassem EH, et al. Authors' reply. $N$ Engl F Med 1998;338:1849-50. 